Authors: M Slabbert and HJ Edeling

THE ROAD ACCIDENT FUND AND SERIOUS INJURIES: THE NARRATIVE TEST

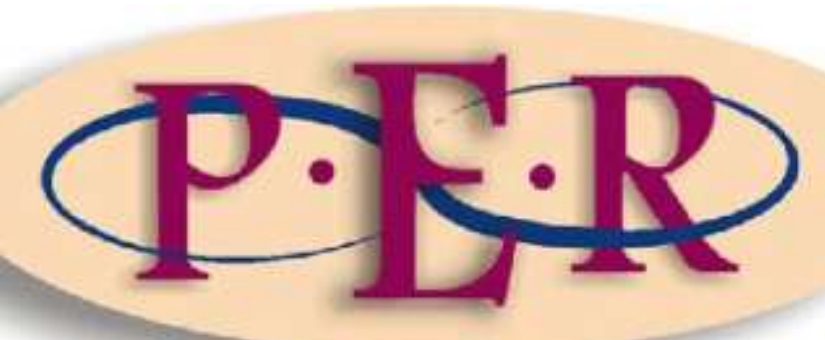

2012 VOLUME 15 No 2

http://dx.doi.org/10.4314/peli.v15i2.10 


\title{
THE ROAD ACCIDENT FUND AND SERIOUS INJURIES: THE NARRATIVE TEST
}

\author{
M Slabbert ${ }^{\star}$ \\ H J Edeling*
}

\section{Introduction}

The Road Accident Fund Act 56 of 1996 has for many years been a bone of contention between lawyers, the government and physicians. In general, lawyers want to get as much as they can from litigation ${ }^{1}$ against the Road Accident Fund (RAF), ${ }^{2}$ government wants to pay as little as possible ${ }^{3}$ and doctors want patients to get what they rightly deserve due to their physical and/or mental losses. Section 3 of the Act explains the objective of the Fund as the payment of compensation in accordance with the Act for loss or damage wrongfully caused by the driving of motor vehicles. ${ }^{4}$ The Act was signed by the President on 24 October 1996 and it commenced on 1 May 1997. ${ }^{5}$ The long anticipated Road Accident Fund Amendment Act 19 of 2005 came into effect on 1 August 2008.

* Magda Slabbert. BA (Hons) HED B PROC LLB LLD (UFS). Professor Department of Jurisprudence, University of South Africa, slabbm@unisa.ac.za.

* Herman J Edeling. MBBCh (Wits) FCS (SA) (Neuro). Fellow of the College of Surgery with Neurosurgery Certified Independent Medical Examiner, edeling@emlct.com.

1 Venter Pretoria News 1.

2 The Fund is an organ of state established in terms of $\mathrm{s} 2$ of the Road Accident Fund Act 56 of 1996.

3 The Road Accident Amendment Act 19 of 2005 limits the RAF's liability for compensation in respect of claims for non-pecuniary loss (general damages) to instances only where a serious injury has been sustained. In Mngomezulu v RAF Unreported case no 4643/2010, Gauteng High Court the court pointed out that road accident victims are constantly faced with ill-founded, spurious and brazen attempts to delay finality of their matters.

4 Section 5 Road Accident Fund Act 56 of 1996: "The Fund shall procure the funds it requires to perform its functions - (a) by way of a Road Accident Fund levy as contemplated in the Customs and Excise Act, 1964 and (b) by raising loans".

5 In Engelbrecht $v$ Road Accident Fund 20076 SA 96 (CC), Kondile AJ, writing for the Constitutional Court, stated that the legislature's primary concern in enacting the Act remained the same as it had been in respect of all the preceding statutes, beginning with the Motor Vehicle Insurance Act 29 of 1942. The relevant legislative history since 1942 is related in Law Society of South Africa v Minister of Transport 2011 1 SA 400 (CC) para 17-21. 
This Amendment Act limits the RAF's liability for compensation in respect of claims for non-pecuniary loss (general damages) ${ }^{6}$ to instances where a "serious injury" has been sustained. ${ }^{7}$ The Amendment Act also abolishes a motor accident victim's common law right to claim compensation from a wrongdoer for losses which are not compensable under the RAF Act, and it limits the amount of compensation that the RAF is obliged to pay for claims for loss of income or a dependant's loss of support arising from the bodily injury or death of a victim of a motor accident. This article deals only with the concept of "serious injury" and not with the other limitations in the Act.

According to the Act a medical practitioner has to determine whether or not the claimant has suffered a serious injury by undertaking an assessment prescribed in the Regulations to the Act. ${ }^{8}$ The practitioner performing the injury assessment has to prepare an RAF $4^{9}$ report. Preparation of the report requires completion and signage of the RAF 4 form and in many cases the attachment of annexures and/or substantiating reports. When compiling the report, the medical practitioner must first have regard to a list of non-serious injuries. ${ }^{10}$ Secondly the medical practitioner must assess the injury in terms of the American Medical Association's Guides to the Evaluation of Permanent Impairment, Sixth Edition (hereafter referred to as the AMA Guides). ${ }^{11}$ If the injury is found to have resulted in 30 per cent or more impairment of

6 "Non pecuniary loss" comprehends damages under the heads more commonly referred to in South Africa as "general damages". Damages in respect of "pecuniary loss" are usually referred to as "special damages" in South African delictual law. Compensation for the loss of earning capacity, which properly falls to be characterised as a head of "general damages" in South African legal parlance, is nevertheless claimable as pecuniary loss under the Act under the label "future loss of income", subject to maximum limits determined in accordance with s 17(4)(c) read with s 17(4A) of the Act. See Daniels v RAF Unreported case no 8853/2010, Western Cape High Court fn 4.

7 Road Accident Amendment Act 19 of 2005.

8 Road Accident Fund Act 56 of 1996: Road Accident Fund Regulations, 2008. GG 31249, Notice number 770 of 21 July 2008, The Regulations became effective on 1 August 2008. See s 9 of the Regulations.

9 http://www.raf.co.za [date of use 19 Dec 2011].

10 Section 3(b)(i) of the Regulations (n 8). "The Minister may publish in the Gazette, after consultation with the Minister of Health, a list of injuries which are for purposes of section 17 of the Act not to be regarded as serious injuries and no injury shall be assessed as serious if that injury meets the description of an injury which appears on the list". Such a list has not yet been published.

11 Rondinelli et al Guides to the Evaluation of Permanent Impairment. Regulations (n 8) section 3(1)(ii) and 3(1) (iv). 
the whole person, according to the methodology provided for in the AMA Guides, the injury should be assessed as serious. ${ }^{12}$

The final step of the report will follow only where the injury is not listed on the "nonserious injuries" list, and where the injury is considered to have resulted in less than 30 per cent of WPI (whole person impairment). In this case the medical practitioner should apply the "narrative test". According to this test the medical practitioner should consider if the injury has resulted in any of the following consequences: "serious long-term impairment or loss of a body function, permanent serious disfigurement, severe long-term mental or severe long-term behavioural disturbance or disorder, or the loss of a foetus". ${ }^{13}$

As is discussed in detail below, there are three major reasons that the AMA Guides is not adequate to the intended task. In an apparent attempt to compensate for these inadequacies the narrative test has been designed as an alternative method of assessing serious injuries. The need for the narrative test arises particularly under two groups of circumstances; namely when the nature of the impairment cannot be dealt with adequately by the methodology of the AMA Guides, and when the circumstances of the injured result in serious disability even though the impairment taken in isolation may not have been seen as serious.

This article discusses reasons why the Regulations do not fulfil the requirements of the Act; reasons why the AMA Guides is not adequate to the task; the impact of the circumstances of an injured person on disability; problems with the existing wording of the narrative test; shortcomings on the RAF 4 form; the administrative process and the appeals tribunals. Reference is also made to court cases in which the narrative test was analysed. In conclusion, recommendations are made in relation to the effective use of the narrative test and the completion of RAF 4 reports in line with the requirements of the Act, how the Regulations and RAF 4 form could be improved, and more relevant training of doctors, lawyers and administrators.

12 Section 17 Road Accident Fund Act 56 of 1996. See also the Regulations (n 8) s 2(a). The determination of the seriousness is also important as the RAF will bear the costs of the assessment only if the claimant's injuries are found to be serious.

13 RAF 4 form point 5. The form is available on the website: http://www.raf.co.za. [date of use 19 Dec 2011]. 


\section{Reasons why the Regulations do not fulfil the requirements of the Act and inherent deficiencies in the AMA Guides}

The assessment of the seriousness of an injury for the purpose of the awarding of general damages should be conducted in terms of the method provided for in the Regulations promulgated in terms of the RAF Act. ${ }^{14}$ The Regulations "define" a serious injury as a 30 per cent WPI according to the AMA Guides. ${ }^{15}$ There are three major reasons that the $A M A$ Guides is not adequate to the intended task.

Firstly, the Amendment Act stipulates in section 17(1A)(a) that the "Assessment of a serious injury shall be based on a prescribed method adopted after consultation with medical service providers and shall be reasonable in ensuring that injuries are assessed in relation to the circumstances of the third party". In highlighting the importance of "the circumstances of the third party", the Act therefore prescribes an assessment of "disability" as opposed to an assessment of "impairment".

Contrary to this important and just provision of the Act, the Regulations prescribe the use of the AMA Guides, which in turn prescribes an "impairment" rating system. For practical purposes this system excludes consideration of the circumstances of the injured person. As clearly stated in the AMA Guides, they do not purport to be and cannot on their own be considered to be guides to permanent disability rating. ${ }^{16}$

The AMA Guides defines impairment and disability as follows. Impairment: "a significant deviation, loss, or loss of use of any body structure or body functions in an individual with a health condition, disorder, or disease".${ }^{17}$ Disability is defined as: "activity limitations and/or participation restrictions in an individual with a health condition, disorder, or disease". ${ }^{18}$ The AMA Guides goes further and states: "The Guides is not intended to be used for direct estimates of work participation restrictions. Impairment percentages derived according to the Guides' criteria do not directly measure work participation restrictions".

14 Section 17(1A) Road Accident Fund Act 56 of 1996.

15 Regulations (n 8) s 3(1)(b)(ii).

16 Rondinelli et al Guides to the Evaluation of Permanent Impairment 5.

17 Rondinelli et al Guides to the Evaluation of Permanent Impairment 5.

18 Rondinelli et al Guides to the Evaluation of Permanent Impairment 5. 
The AMA Guides therefore does not serve the purpose of the Act. Permanent impairment is only one of many components that contribute to permanent disability. The seriousness of an injury relates to the degree of disability far more than to the degree of impairment alone. This is because of the major contributions to the seriousness of the permanent sequelae of injuries that are made by geographical, economic, housing, transport, employment and other factors, all of which are contemplated in the meaning of disability but not in the meaning of impairment.

Section 17(1A)(a) of the RAF Act specifically requires that "Assessment of a serious injury shall be based on a prescribed method adopted after consultation with medical service providers and shall be reasonable in ensuring that injuries are assessed in relation to the circumstances of the third party" (own emphasis). In other words it is a requirement in the Act to take an injured person's circumstances into consideration, but this requirement is not included in the Regulations except for indirect application in the narrative test. According to social justice relevant external factors in addition to impairment should be taken into consideration as well. Professional experience abounds with examples of major differences between the impact of the same injury and the same impairment on different persons in different social and geographical circumstances, on the ability to function, on the ability to perform the activities of daily life, and therefore on the quality of life. To ignore these important contributing factors will exclude from the system of compensation the major suffering of countless impoverished and otherwise disadvantaged victims of road accidents.

Many such victims are necessarily more susceptible to environmental obstacles than wealthier persons who have access to mechanical or domestic amenities that poor people lack. Many poor persons have limited educational or other vocational skills and they are limited to performing manual work. That means that the same physical impairment percentage will have a greater impact on a poor person who is qualified to perform manual labour only and who has limited resources, than on persons with a wider range of skills, facilities, transport and access to healthcare. What is socially unjust is the provision in the Regulations that prescribes the use of an inappropriate instrument to measure serious injury. The Regulations prescribe an instrument in the AMA Guides that measures only one of the major elements that contribute to the seriousness of an injury, namely "impairment". The other major element, namely the 
"circumstances of the victim" as specified in the RAF Act, is not specifically addressed by the AMA Guides. In some instances it is addressed by way of grade modifiers, but in such a minute way as to be practically ineffective.

Furthermore, no consideration is given to the more severe suffering and impairment during the months or years following the accident prior to the date of MMI (maximal medical improvement), as the impairment rating relates only to the altered status for the rest of the person's life after the date of MMI.

If the intention of awarding compensation for "general damages" is to compensate victims for "non-pecuniary damages" such as "pain and suffering and losses of amenities and enjoyment of life", it is scientifically misguided and socially unjust to determine those victims who should receive compensation for "general damages" by use of an instrument that according to its own description fails to award any more than a token percentage to chronic pain in the vast majority of cases. This is because it has thus far proved to be impossible to apply consensus-based percentages to the suffering associated with pain.

The second reason that the AMA Guides is not adequate to the intended task relates to inherent inadequacies in the Guides in terms of their usage for the assessment of "general damages" as contemplated in South African practice. General damages are intended to provide compensation for "pain, suffering and losses of amenities and enjoyment of life". The suffering of any injured person is an intensely personal and subjective experience. Whereas the Guides is good at the assessment and comparison of concrete elements of impairment that are amenable to objective measurement, such as the degrees of loss of motion of an injured joint, they fall short in the assessment and comparison of equally important but more abstract and subjective impairment associated with suffering. In the result the Guides does make provision for small and inconsistent impairment percentages for pain and loss of amenities, but these are ineffectual in meeting the 30 per cent of WPI benchmark provided for in the Regulations.

Chapter 3 of the AMA Guides, "Pain-Related Impairment", provides that when pain has been identified by the patient as a major problem, and when a number of other 
criteria have been met, the degree of pain-related impairment is to be assessed according to the prescribed "Pain Disability Questionnaire". ${ }^{19}$ According to this method, when the "Degree of Pain-Related Impairment" is classified by the AMA Guides as "Extreme", ${ }^{20}$ a "Whole Person Impairment" of only 3 per cent is awarded. This means that a victim who is disabled due to chronic pain (such that the victim is unable to work; needs help with personal care; travels only to see doctors; cannot lift objects off the floor, bend, stoop or squat; cannot walk or run; has loss of income; is on pain medication throughout the day; is forced by pain to see doctors weekly; is unable to see people who are important to the victim as much as he or she would like; suffers total interference with important recreational activities and hobbies; needs help to complete everyday tasks; suffers severe depression/tension; and suffers emotional problems caused by pain that interfere with family, social or work activities) will not receive any compensation for general damages because 3 per cent falls far short of the prescribed minimum requirement of the 30 per cent of WPI required by the Regulations.

Further to the above, internal inconsistencies are apparent in other sections of the Guides. Certain specific severe pain syndromes are awarded different percentages. The worst class of migraine headache, described as "severe disability", is awarded 5 per cent of WPI. ${ }^{21}$ The worst class of trigeminal or glossopharyngeal neuralgia, described as "severe, uncontrolled facial neuralgic pain that interferes with performance of activities of daily living (ADL)", is awarded 6 to 10 per cent of WPI. ${ }^{22}$ The worst class of neurogenic pain in miscellaneous peripheral nerves, described as "severe neurogenic pain in an anatomic distribution", is awarded 4 to 5 per cent of WPI. ${ }^{23}$ All of these percentages fall far short of the prescribed minimum of 30 per cent of WPI.

All victims with "severe" and the majority of victims with "very severe" complex regional pain syndrome in the lower extremities, and who meet stringent diagnostic criteria, are awarded ratings between 10 and 28 per cent of WPI depending on grade

19 Rondinelli et al Guides to the Evaluation of Permanent Impairment 40.

20 Rondinelli et al Guides to the Evaluation of Permanent Impairment 40 Table 3-1.

21 Rondinelli et al Guides to the Evaluation of Permanent Impairment 342.

22 Rondinelli et al Guides to the Evaluation of Permanent Impairment 343.

23 Rondinelli et al Guides to the Evaluation of Permanent Impairment 344. 
modifiers (26 to 70 per cent lower extremity impairment rating), while only the two worst grades of the class 4 "very severe" are awarded ratings above 30 per cent, namely ratings of 32 or 36 per cent of WPI ( 80 or 90 per cent lower extremity impairment rating). ${ }^{24}$ The application of the prescribed criterion of 30 per cent of WPI according to the AMA Guides will deny compensation for general damages to many victims who suffer severe chronic pain-related disability stemming from serious and life-altering injuries. It is inconceivable that this unconscionable effect could have been the intention of the Act.

The third reason that the AMA Guides is not adequate to the intended task relates to inherent difficulties in the measurement of the more abstract though objectively evident impairments associated with brain damage on the one hand and the psychological sequelae of injuries on the other. The "neurocognitive" and "psychiatric" sections of the Guides are less scientifically clear and less consistent than the "orthopaedic" and "neurophysical" sections of the Guides.

If a person suffers a brain injury, for example, physicians assessing the injured are to use the Mental Status Exam for the Neurologically Impaired Patient. ${ }^{25}$ The application of the test is qualitative and not quantitative, and the assessment is open to a wide degree of inter-observer discrepancy. Add to that the Criteria for Rating Neurological Impairment due to Alteration in Mental Status, Cognition, and Highest Integrative Function (MSCHIF) ${ }^{26}$ and the situation is exacerbated in the first two alternative methods. There is no indication as to the criteria for rating a mental impairment as "mild", "moderate" or "severe", which is the determination upon which classifications should be made in Classes 1, 2 and 3 .

24 Rondinelli et al Guides to the Evaluation of Permanent Impairment 538-542. Examples 16-17 on 540-542 describe the extent of suffering and impairment of a woman who is awarded a $15 \%$ whole person impairment rating. Pages 450-454 show that similar comments apply to cases of complex regional pain syndrome in the upper extremities, except that the upper extremities impairment ratings are multiplied by $60 \%$ to calculate whole person impairment ratings instead of $40 \%$ as in the case of the lower extremities, and that victims with all grades of class 3 "severe" complex regional pain syndrome fall short of the prescribed minimum level for compensation, with whole person impairment ratings varying between 16 and $29 \%$ depending on grade modifiers (26 to $49 \%$ upper extremity impairment ratings), while only those in class 4 , "very severe", qualify for compensation by virtue of whole person impairment ratings of $30 \%$ to $54 \%$ (50\% to $90 \%$ upper extremity impairment ratings). Examples $15-20$ on pages 452 to 454 describes the extent of suffering and impairment of a man who is awarded a $29 \%$ whole person impairment rating.

25 Rondinelli et al Guides to the Evaluation of Permanent Impairment 330 Table 13-7.

26 Rondinelli et al Guides to the Evaluation of Permanent Impairment 331 Table 13-8. 
Chapter 14 of the Guides, entitled "Mental and Behavioural Disorders", deals with psychiatric conditions, while chapter 13 , which is entitled "Central and Peripheral Nervous System", deals with neurological conditions. There is an unfortunate potential ambiguity in the choice of words in that the neurological sequelae of traumatic brain injury typically include mental and behavioural disorders. A doctor compiling a report for an individual with mental and behavioural disorders due to traumatic brain injury can therefore end up using the psychiatry chapter instead of the neurology chapter. Adding to the problem, table 14-10 of the psychiatry chapter, which deals with "GAF" (Global Assessment of Functioning) is reproduced as 13-10 in the neurology chapter, therefore prescribing a psychiatric instrument for a neurological condition.

The application of the impairment percentages in tables $14-10$ or $13-10$ to survivors of traumatic brain injury leads to significant under-assessment of the seriousness of the injury. For example, a person with major and permanent life-altering sequelae, including the loss of employability, amenities and independence, defined in the Guides as "serious symptoms (e.g., suicidal ideation, severe obsessional rituals, frequent shoplifting) or any serious impairment in social, occupational, or school functioning (e.g., no friends, unable to keep a job)", are awarded 15 per cent of WPI. A person with even worse sequelae, defined in the Guides as "some impairment in reality testing or communication (e.g., speech is at times illogical, obscure, or irrelevant) or major impairment in several areas, such as work or school, family relations, judgement, thinking, or mood (e.g., depressed man avoids friends, neglects family, and is unable to work; child frequently beats up younger children, is defiant at home and is failing at school)", is awarded 20 per cent of WPI. The effect is that such individuals may be denied any compensation for general damages. This could not have been the intention of the legislature.

The above comments are not intended as criticism of the authors of the Guides, who have performed an admirable task in compiling a comprehensive impairment rating system, but are intended to highlight the serious problems and inter-observer discrepancies of a system in which observers are required to apply a percentagebased system to impairments that are objective but abstract, and even more so to impairments that are both subjective and abstract. 
The ideal is that only doctors who have attended a course presented by the author(s) of the Guides should be authorised to compile an RAF 4 report. To date not enough doctors have completed the course and therefore any medical practitioner who is registered in terms of the Health Professions Act 56 of 1974 is at this stage "qualified" to fill in the form or compile a report without necessarily knowing how to employ the AMA Guides. ${ }^{27}$ Medical students are not exposed in their studies to the AMA Guides. In normal clinical practice doctors have no reason to perform assessments under the Guides, which would serve no purpose when treating a patient. There is no external postgraduate training in the Guides in South Africa except for the occasional courses provided under the auspices of the RAF. The effect is that not enough doctors are proficient in the use of the Guides.

Without training in the AMA Guides medical practitioners would not be able to make complex assessments in terms of the Guides. In fact, many medical practitioners who have undergone the standard training in using the Guides still need further experience and study before becoming able to make adequate independent impairment assessments in terms of them.$^{28}$ In many cases assessment under the AMA Guides requires the availability of several specialists in different fields, requiring each to have had training in the use of the Guides. This adds counterproductive complexity and cost to the prescribed assessments. Although it is the intention of the AMA Guides that a single qualified medical practitioner should perform a comprehensive assessment according to the methodology of the Guides, in practice even medical practitioners who are qualified $\mathrm{CIMEs}^{29}$ are sometimes unwilling to transgress into other speciality fields and give opinions in areas of medicine in which they do not have sufficient knowledge.

27 Lists of doctors who have completed the exam offered by the American Board of Independent Medical Examiners are available on the website http://www.abime.org. [date of use 19 Dec 2011]. These doctors are referred to as CIMEs - Certified Independent Medical Examiners.

28 In Law Society of South Africa v Minister of Transport 201011 BCLR 1140 (GNP) Fabricius AJ confirmed that the AMA Guides would not be readily comprehensible in important respects to anyone who was not proficient in the medical assessment of bodily impairment.

29 See fn 27 above. 


\section{The narrative test}

After the completion of an assessment, where the result is less than a 30 per cent WPI, the claimant may well be able to show that he or she qualifies for compensation by the RAF in terms of the narrative test.

In Mngomezulu $v$ RAF ${ }^{30}$ the court held that with regard to assessing the injury after an accident as serious in terms of the amendments to the RAF Act 1996, ${ }^{31}$ the two alternatives tests that can be used are: the "whole person impairment test as per Regulation 3(1)(b)(ii) and the so-called narrative test as per Regulation 3 (1)(b)(ii)(aa)-(dd)". The narrative test is a safety net providing an alternative assessment where the AMA Guides would not result in a finding of serious injury according to the prescription of the Regulations. ${ }^{32}$

In the Mngomezulu case the plaintiff was involved in a hit-and-run motor vehicle accident, as a result of which he suffered injuries. He instituted action against the RAF. The basis for the plaintiff's claim was for general damages via the narrative test in terms of Regulation 3(1)(b)(iii)(aa)-(cc). Various reports and RAF 4 forms had been completed by medical specialists confirming that the injuries he sustained were serious as per the narrative test. The RAF opposed the action.

The RAF contended that the medical practitioners had not completed the RAF 4 form correctly in that they failed to assign a "whole person impairment" rating and instead chose to rely on the narrative test, yet the court pointed out that there was nothing in the Regulations which prevented the plaintiff from being assessed in terms of the narrative test. Either of these tests may be used.

In Daniels and 2 Others $v R A F^{33}$, a woman was struck down by a motor vehicle and sustained severe injuries to her lower leg. As a result of this she was unable to resume her work as her previous employment required her to run about physically. She claimed her injuries were serious within the meaning of section 17(1) of the RAF

30 Mngomezulu v RAF Unreported case no 4643/2010, Gauteng High Court.

31 Road Accident Fund Amendment Act 19 of 2005.

32 Ahmed 2011 Risk Alert Bulletin 6.

33 Daniels v RAF Unreported case no 8853/2010, Western Cape High Court. 
Act and she claimed compensation for general damages. She could not afford to pay the R7 000 required for a serious injury assessment report and submitted a request to the Fund for financial assistance. The Fund refused this request and contended that it was liable to pay the costs of a serious injury assessment only in the event that the claimant had sustained serious injuries that resulted in not less than 30 per cent WPI. The Fund did not consider the narrative test adequate to ascertain the seriousness, or lack thereof of the injury.

In the court papers the Fund explained that they will assist a person financially only if there is a prima facie indication of a serious injury. It further stated that the narrative test is there only to cover the isolated and rare cases where the whole person impairment test fails. It is thus a fallback position. ${ }^{34}$

The court stated that the narrative test falls to be applied as an integral part of any serious injury assessment and this is indeed confirmed by the contents of part 5 of the RAF 4 form, which gives effect to regulation 3(1)(b0(iii). There is nothing in the Regulations which suggest that the narrative test should be applied only in "rare and isolated cases". The decision by the Fund to decline the applicant's request in terms of regulation 3(2)(b) was set aside.

The whole person impairment test is largely based on the table of activities of daily living, ${ }^{35}$ which includes basic activities such as grooming, toileting, feeding, dressing and bathing, as well as advanced activities such as driving a car, sexual function, money management, shopping, housework and moderate activities.

It is submitted that a person should be tested not only against activities of daily living when using the narrative test, but also according to the roles he or she plays in life. By way of example, life roles include being a mother, a husband, a friend, an accountant, a professor, a politician, a sportsperson and so on. For example, if an academic or a professional practitioner with a pre-accident IQ of 130 has been reduced to an IQ of 115 by a head injury, the impairment may seem minor as many people excel on an IQ of 115 . However, for the head-injured academic or

34 Bertelsmann 2011 Risk Alert Bulletin 6.

35 Rondinelli et al Guides to the Evaluation of Permanent Impairment 323. 
professional practitioner the injury results in serious disability as the loss of intellectual capacity renders him or her unable to work or engage in other life roles as before. In many cases the result is that the individual suffers permanent and distressing losses of status, dignity and respect.

\subsubsection{Problems with the RAF 4 form and the narrative test}

The Act stipulates in Section 24(2)(a) that "The medical report shall be completed on the prescribed form by the medical practitioner who treated the deceased or injured person for the bodily injuries sustained in the accident from which the claim arises, ...". The form referred to in Section 24 is the RAF 4 report form. The form states at the beginning, amongst other things, that a claim for non-pecuniary "general damages" or "pain and suffering" will not be considered unless the report is duly completed and submitted. The RAF 4 form must be completed by a medical practitioner registered in terms of the Health Professions Act 56 of 1974. Finally the report must be compiled by using the tables and page numbers from the $A M A$ Guides.

Problems arise in relation to the loose use of the word "injury" where the context appears to relate to complications, impairment or disability. This can easily lead to confusion. In essence "injury" refers to the physical damage that occurs at the moment of the accident, "complication" to the subsequent pathological developments, "impairment" to the long-term symptoms and losses resulting from the injuries, and "disability" to the effects of the impairment on the various elements of the individual's life taking into account the circumstances.

Point 3 on the form, which relates to non-serious injuries, currently serves no purpose. According to the RAF Act and Regulation 3(1)(b)(i) the Minister may publish in a Government Gazette, after consultation with the Minister of Health, a list of injuries which for the purposes of section 17 of the Act will not to be regarded as serious injuries. The Minister of Transport has to date (2012) not published a list of non-serious injuries. Until such a list is published, medical practitioners performing assessments in terms of the assessment method prescribed in Regulation 3(1)(b) must disregard Regulation 3(1)(b)(i), and therefore point 3 on the form. 
Point 4 refers to the AMA Guides rating which should be completed if the injury sustained does not appear on the non-serious list of injuries. In point 4.1 the doctor is required to describe the nature of the motor vehicle accident, despite the fact that he or she often has no knowledge or limited knowledge of what happened and he or she must therefore speculate. It would be more relevant to ask the doctor whether he or she is satisfied that the injured was indeed injured in a motor vehicle accident, and whether the injuries claimed for were in fact caused by the motor vehicle accident in question.

The order of the report to be completed is troublesome and there are glaring omissions. There is no specific provision for recording the injuries or complications. The doctor must first indicate the medical treatment rendered (4.2) to the injured before indicating a diagnosis (4.4) and before recording the medical history (4.7), the social and personal history (4.8) or the educational and occupational history (4.9) of the injured. It is not clear whether the required diagnosis (4.4) relates to the injury diagnosis or the outcome diagnosis, two different concepts each which is of major importance.

Strangely the form does not call for the doctor to record the percentage of impairment. This is despite the fact that, according to the Guides and according to the RAF, the percentage of impairment is the crux of the matter. No mention of the cut-off point of 30 per cent or more of WPI to determine whether an injury is serious or not is made under point 4 on the RAF 4 form. The only reference to 30 per cent of WPI appears in point 5 , which deals with the narrative test.

The Regulations state in section 3(1)(b)(ii) that if the injury resulted in 30 per cent or more impairment of the whole person, the injury shall be assessed as serious, but if the injury is assessed at below 30 per cent (using the AMA Guides) it may nonetheless be considered a serious injury for one or more of many reasons, in which case the doctor should apply the narrative test (Point 5 on the RAF 4 form).

Point 5 uses the words "serious" and "severe", yet the meanings of the words are not defined in the Act, the Regulations or the RAF 4 form. The undefined choice of these words leaves their interpretation open to the personal experience and 
subjective views of different doctors, with the obvious potential for wide interobserver discrepancies on the same subject.

In the narrative test as set out in point 5.1, the doctor must consider if the injuries have resulted in "serious long-term impairment or loss of a body function". The word "serious" at this point takes the matter no further than the word "serious" in the heading of the form or in point (c) on the first page of the form. Similar comments relate to point 5.2, "permanent serious disfigurement". The doctor may just as well have simply been asked to consider whether the injuries were "serious" or not, thereby dispensing with the need for the Guides and the perplexing form.

In point 5.3 the doctor must consider if the injuries have resulted in "severe long-term mental or severe long-term behavioural disturbance or disorder". It should be remembered that the form stipulates that the narrative test should be used only once the doctor has determined that the WPI, as provided for in the Guides, is below 30 per cent, yet the doctor feels that the injuries are serious. Because of the choice of words, the ambiguity and difficulties outlined above in relation to the use of chapter 13 and chapter 14 of the Guides may influence the doctor's consideration of point 5.3 of the narrative test.

It is clear that the wording of the narrative test, as it appears in the Regulations and on the RAF 4 form, is problematic. Despite its apparent purpose in complying with the provisions of the Act by remedying inadequacies in using the Guides as a method of determining serious injury, it makes no mention of the injured person's circumstances, disability, pain, suffering or loss of enjoyment of life. 


\section{The procedure after an RAF 4 report has been completed}

After completion of an RAF 4 report, whether the whole person impairment test or the narrative test was used, it is submitted to the RAF. Peculiarly, members of the administrative staff of the RAF are then required to review the medical report and decide whether or not they accept it. In practice it turns out that most claims are rejected, suggesting that the administrative staff disagree with the medical findings. The basis on which they disagree begs explanation.

In the Mngomezulu case ${ }^{36}$ the court provided guidelines with regard to the rejection of a serious injury claim - the RAF must furnish the plaintiff with reasons why the RAF 4 report was rejected ${ }^{37}$ - but the court stated that this applies only to procedural aspects of the assessment and provided the following examples: where the report is completed by an unqualified person; the assessment is not conducted in terms of the prescribed methods; the impairment evaluation reports for a specific body part are not attached as required; or the report is not completed in all particularity. In Smit and Another $v R A F^{38}$ it was also stated that sufficient reasons must be given justifying a rejection of a claim.

The RAF can also request the plaintiff to make him or herself available for further assessment by their own appointed medical practitioner at the RAF's expense. ${ }^{39}$ This "second opinion" procedure would apply to the actual material medical findings of the assessment. For the RAF to succeed with this option, it must provide dissenting medical opinion. Only in cases of dissenting medical opinion should matters be referred to an appeal tribunal. ${ }^{40}$

36 Mngomezulu v RAF Unreported case no 4643/2010, Gauteng High Court.

37 Regulations (n 8) s 3(3)(d)(i).

38 Smit v RAF Unreported case no 47697/2009, Gauteng High Court.

39 Regulations (n 8) s 3(3)(d)(ii).

40 Ahmed 2011 Risk Alert Bulletin 6-7. 


\subsection{Appeal Tribunal}

The prescribed appeal tribunals consist of three independent medical practitioners with expertise in the appropriate areas of medicine appointed by the Registrar, ${ }^{41}$ who shall designate one of them as the presiding officer of the appeal tribunal. ${ }^{42}$ The Registrar may also appoint an additional independent health practitioner with expertise to assist the tribunal in an advisory capacity. ${ }^{43}$ At present only medical practitioners who have attended the training by the authors of the AMA Guides and who have passed the exam of the ABIME (American Board of Independent Medical Examiners) are eligible for selection ${ }^{44}$.

It appears that the RAF provides a list of doctors who have passed the ABIME exam to the HPCSA (the Health Professions Council of South Africa) for use in appointing members of appeal tribunals. The appointment of tribunal members may therefore lack independence and credibility. Lists published independently by ABIME, which are available, should actually be used by the HPCSA.

The Amendment Act and the Regulations are in force in South Africa in relation to all injuries sustained since 1 August 2008, yet the first tribunal sat in 2011, resulting in major delays in dealing with claims rejected by the RAF. ${ }^{45}$

\section{$5 \quad$ Recommendations}

In amongst the doom and gloom there is a beacon of light. This is to be found on page 331 of the AMA Guides in Table 13-8, in the method prescribed in its third row "Description". ${ }^{46}$ This method, which achieves the status of a true disability assessment, accords with the provisions of the Act, serves social justice and accords with medical judgment and common sense. Whereas the AMA Guides prescribes

41 The Registrar of the Health Professions Council of South Africa established in terms of $\mathrm{s} 2$ of the Health Professions Act 56 of 1974.

42 Regulations (n 8) s 8(b).

43 Regulations (n 8) s 8(c).

44 The author(s) of the AMA Guides come to SA twice a year to give training on the Guides. South African doctors who want to complete RAF 4 must do the training. Each individual can decide to write the exam in order to become a CIME. They can write the exams in SA or in the USA.

45 Regulation (n 8) s11 sets out the powers of the appeal tribunal.

46 Rondinelli et al Guides to the Evaluation of Permanent Impairment 331. 
this method in the evaluation of impairment related to alteration in mental status, cognition and higher integrative function flowing from brain injuries, it is our submission that this method is equally applicable to other forms of impairment, whether of a physical, pain-related or psychological nature. For these reasons we recommend that the method prescribed in the third row "Description" of Table 13-8 in the AMA Guides should be used mindfully in applying the narrative test, irrespective of the nature of the injury or impairment.

According to this "Description" in the Guides, classes and percentages of WPI are defined as follows : - (our own emphasis)

Class 0 - Normal - 0 percent - defined as "Normal";

Class 1 - Mild abnormalities - 1 percent to 10 percent - defined as "Alteration in MSCHIF but patient is able to assume all usual roles and perform ADLs";

Class 2 - Moderate abnormalities - 11 percent to 20 percent - defined as "Alteration in MSCHIF that interferes with ability to assume some normal roles or perform ADLs";

Class 3 - Severe abnormalities - 21 percent to 35 percent - defined as "Alteration in MSCHIF that significantly interferes with ability to assume normal roles or perform ADLs"; and

Class 4 - Most profound abnormalities - 36 percent to 50 percent - defined as "Alteration in MSCHIF that prohibits performance of normal roles or performance of ADLs".

The relevance of this method is that it relates the degree of the problem to the performance of "ADLs" as well as to "normal roles" (life roles such as a mother, a husband, an accountant, a professor, a gardener, a stamp collector, an athlete, a pianist, a dancer, a manual labourer etc.).

In the application of this system the classification of an injured person as Class 0 , Class 1 or Class 4 is fairly simple and self-evident, as long as sufficient detail has been canvassed in relation to the person's previous circumstances, ADLs and roles, as well as the extent to which they have changed as a result of the injuries. 
Class 2 and Class 3 require more thought. The useful and essential discriminator prescribed by the AMA Guides in determining whether an individual should be classified as Class 2 or Class 3 is the determination of if the interference with the ability to assume normal roles or perform ADLs is to be regarded as "some" or "significant". In our submission an interference should be regarded as "some" when it is clearly present and determinable but it does not result in particular distress or suffering or does not really matter to the injured person. In contrast an interference should be regarded as "significant" when it does result in ongoing distress or suffering or does really matter to the injured person. Mindful application in this manner meets the essential requirement of the assessment of "pain, suffering and losses of amenities and enjoyment of life". It is furthermore considered that it is within the capacity of any sensible medical practitioner to make this determination, as long as sufficient detail has been canvassed.

It is understandable that there should be prescribed procedures to facilitate a fair process for everyone. Much has been done in the past to streamline the process and that is appreciated, yet the feeling arises that with a few more changes a lot can be done to make the process more effective. Firstly, the Act and the Regulations in terms thereof should address the same issues. As pointed out above, the Act refers to the "circumstances" of the injured party but the Regulations do not mention them specifically. The prescribed AMA Guides is a useful instrument, but for many reasons it cannot be applied to South African needs without additional measures. In particular the focus on impairment rather than disability needs rethinking.

Training in the use of the AMA Guides is currently given by one of the authors of the Guides under the auspices of the RAF, which cannot be seen as independent. The narrative test is not being addressed in the existing training. In the South African context the narrative test seems to be extremely relevant, but proper understanding thereof is crucial to its correct and just implementation. It is proposed that additional training in the interpretation of serious injuries in the South African context should be provided by South African experts under the auspices of an independent body.

The RAF 4 form should be adapted to be more meaningful. The order of points 4.1 to 4.9 of the form should be brought in line with common sense and the scientific 
methods used in medical diagnosis. More importantly, points should be added calling for descriptions of the injuries, any complications of the injuries, the loss of ADLs and the loss of life roles, as well as the impairment percentage. Words also need to be defined and used accurately.

The evaluation of RAF 4 reports by administrators of the RAF needs attention as well. Members of staff should be trained in the meaning and application of the narrative test. They should also be made aware that the narrative test is not to be applied only in rare instances where the whole person impairment raring falls below 30 percent. They should know that the doctor completing the report has a choice between using the whole person impairment rating or following the narrative test. Claims should not be declined off-hand as the process thereafter is cumbersome and costly. If administrators have sufficient knowledge and use experts to assist them, there should be less need for cumbersome and costly reviews by appeal tribunals.

In using experts as tribunal members the HPCSA should consult the independent list of CIMEs from ABIME rather than lists that may have been edited by the RAF. As the RAF is a party to a dispute before an appeal tribunal it cannot rightfully be involved in driving the process. More importantly, over and above any training in the use of the AMA Guides, tribunal members should have understanding of the provisions of the Act and of the narrative test, as well as experience of disability assessment in South Africa.

\section{Conclusion}

In Road Accident Fund and Another $v$ Mdeyide ${ }^{47}$ the RAF is described as "a hugely important public body which renders an indispensible service to vulnerable members of society". ${ }^{48}$ The majority judgment reflected an acknowledgement of the crucial importance of a "properly administered" Fund to the upholding of "the constitutional values of human dignity, the achievement of equality and the advancement of human

47 Road Accident Fund v Mdeyide 20111 BCLR 1 (CC).

48 Road Accident Fund v Mdeyide 20111 BCLR 1 (CC) para 78. 
rights and freedoms". ${ }^{49}$ Bearing this in mind the seriousness of an injury should be assessed as determined by legislation; the circumstances of the victim should be taken into account; and the true impact of the injuries on the victim's life should be mindfully and appropriately assessed.

The RAF should give just compensation to persons who have suffered due to an accident. The process of claiming general damages is currently experienced as cumbersome, confusing, complicated and socially unjust. This should not be the case. A few sensible alterations to the Regulations and the RAF 4 form, as well as more appropriate training in the assessment of serious injuries in accordance with the Act, should go a long way in streamlining the unwieldy procedures.

The narrative test is extremely important as it is wider than the impairment of the whole person test, but education is needed on the proper application of the test and the formulation of relevant motivations. The evaluation of seriousness relates to more than the medical evaluation of impairment, and other crucial factors need to be taken into consideration.

49 Road Accident Fund v Mdeyide 20111 BCLR 1 (CC) para 80. 


\section{Bibliography}

\section{Ahmed 2011 Risk Alert Bulletin}

Ahmed R "RAF Case Law" 2011 Risk Alert Bulletin (5) 6

Rondinelli et al Guides to the Evaluation of Permanent Impairment

Rondinelli RD et al Guides to the Evaluation of Permanent Impairment $6^{\text {th }}$ ed (American Medical Association Chicago 2008) (AMA Guides)

Bertelsmann 2011 Risk Alert Bulletin

Bertelsmann E "Useful Tips for MVA Practitioners" 2011 Risk Alert Bulletin (4) 6

Venter Pretoria News

Venter Z "Greedy' lawyers punished: Six struck off the roll, seven suspended; must repay millions to RAF' Pretoria News 30 September 2011

\section{Register of case law}

Daniels v RAF Unreported case no 8853/2010, Western Cape High Court Engelbrecht $v$ Road Accident Fund 20076 SA 96 (CC)

Law Society of South Africa v Minister of Transport 201011 BCLR 1140 (GNP)

Law Society of South Africa v Minister of Transport 20111 SA 400 (CC)

Mngomezulu v RAF Unreported case no 4643/2010, Gauteng High Court

Road Accident Fund v Mdeyide 20111 BCLR 1 (CC)

Smit v RAF Unreported case no 47697/2009, Gauteng High Court

\section{Register of legislation}

Health Professions Act 56 of 1974

Motor Vehicle Insurance Act 29 of 1942

Road Accident Fund Act 56 of 1996

Road Accident Fund Act 56 of 1996: Road Accident Fund Regulations, 2008. Government Gazette Number 31249, Notice Number 770 of 21 July 2008 
Road Accident Amendment Act 19 of 2005

\section{Internet}

http://www.raf.co.za [date of use 19 Dec 2011]

http://www.abime.org [date of use 19 Dec 2011]

\section{List of abbreviations}

ABIME

$A D L$

AMA

CIME

GAF

HPCSA

IQ

$\mathrm{MMI}$

MSCHIF

RAF

WPI
American Board of Independent Medical Examiners

Activities of daily living

American Medical Association

Certified Independent Medical Examiner

Global assessment of function

Health Professions Council of South Africa

Intelligent Quoficient

Maximal medical improvement

Mental status, cognition, and highest integrative function

Road Accident Fund

Whole person impairment 